\title{
DE CLITEMNESTRA A CHRISTINE MANNON: ¿MUJERES VILLANAS O VENGADORAS?
}

\author{
From Clytemnestra to Christine Mannon: Villainesses or Avengers?
}

\author{
Gilda Pacheco Acuña ${ }^{1}$
}

\begin{abstract}
RESUMEN
El artículo presenta la comparación literaria de dos personajes femeninos: Clitemnestra en la trilogía de Esquilo, conocida como La Orestía, y Christine Mannon en la trilogía de Eugene O’Neill titulada Mourning Becomes Electra (A Electra le sienta bien el luto). Siguiendo preceptos teóricos de literatura comparada y de enfoques de género, se analizarán las similitudes, diferencias, logros y limitaciones de estas dos fuertes y polémicas heroínas. Sus pensamientos y acciones son usualmente criticados, pues serán descritos y condicionados por las percepciones de dos escritores masculinos pertenecientes a sociedades patriarcales de sus respectivas épocas.
\end{abstract}

Palabras clave: Personajes femeninos, literatura comparada, La Orestía, Mourning Becomes Electra, Esquilo, Eugene O’Neill.

\begin{abstract}
This article presents the literary comparison of two female characters: Clitemnestra in the trilogy of Esquilo, named $L a$ Orestía, and Christine Mannon in the trilogy of Eugene O’Neill entitled Mourning Becomes Electra. Following theoretical precepts of comparative literature and of gender approaches, the similarities, differences, achievements and limitations of these two strong and polemic heroines will be analyzed. Their thoughts and actions are usually criticized since they will be depicted and conditioned by the perceptions of two male writers who belong to patriarchal societies of their respective epochs.
\end{abstract}

Key Words: Female characters, comparative literature, La Orestía, Mourning Becomes Electra, Esquilo, Eugene O’Neill.

\section{Introducción}

Este artículo consiste en la comparación literaria de dos personajes femeninos provenientes de dos trilogías escritas por dramaturgos de renombre: una de ellas es La Orestía, o también llamada La Orestíada, escrita en el año 458 a.C. por Esquilo, considerado el primer gran representante de la tragedia griega, y la otra es Mourning Becomes Electra (A Electra le sienta bien el luto), escrita en 1931 por Eugene O’Neill, a su vez considerado el padre del drama estadounidense. Se aclara que aunque ambas trilogías, como el término mismo lo indica, se dividen en tres partes, para efectos de este artículo se analizará solamente la primera parte de cada trilogía, es decir, la titulada “Agamenón”

\footnotetext{
${ }^{1}$ Universidad de Costa Rica. Profesora de la Escuela de Lenguas Modernas. Costa Rica. Correo electrónico: gilda.pacheco@ucr.ac.cr
}

Recepción: 13-12-2017. Aceptación: 04-04-2018. 
en la obra de Esquilo, y la titulada “Homecoming” (“Retorno al hogar”) en la obra de O’Neill. También se especifica que de los personajes femeninos que aparecen en estas dos primeras partes de las antes mencionadas trilogías, Clitemnestra y Christine Mannon, respectivamente, serán objeto de estudio para el análisis comparativo propuesto.

Es extraordinario pensar que son varios siglos los que separan a estas dos obras, pero aun así, sus similitudes son claras. Es más, al leer la crítica literaria sobre la obra del dramaturgo estadounidense, se indica que ciertamente O’Neill se basó en la trilogía de Esquilo para diseñar la propia. Entonces, es pertinente destacar que el concepto de "influencia”, el cual se presenta en este caso al comparar las dos obras, ha sido uno de los temas más discutidos y de los más polémicos en literatura, y a la vez es un tema bastante recurrente en el campo de la literatura comparada, donde incluso es catalogado como una categoría llamada “estudios de influencia”. Harold Bloom, por ejemplo, desarrolla este aspecto en su obra titulada The Anxiety of Influence: A Theory of Poetry. En su libro, el crítico norteamericano dice que los escritores ven con recelo a sus predecesores, pues siempre anhelan presentar algo original para trascender y poder así ser recordados. Pero en el caso de O’Neill con su obra Mourning Becomes Electra, su deuda con Esquilo es explícita y reconocida por el propio dramaturgo estadounidense, lo cual no le genera ni recelo ni ansiedad alguna. Pareciera más bien que O’Neill hace su obra, admirando y emulando en parte a la trilogía de Esquilo, la cual toma de la antigüedad, la adapta y la contextualiza a su tiempo.

Se puede observar, desde el inicio de la obra Mourning Becomes Electra, que O’Neill sitúa a la persona lectora en el exterior para describir la mansión de los Mannon, en donde destaca un pórtico blanco con columnas, asemejando, según indica el texto, a “un templo griego”. Por lo tanto, no es solo la estructura tripartita literaria del dramaturgo griego lo que utiliza O’Neill para diseñar su obra, sino que el propio hogar de sus personajes, el de la familia Mannon, tiene una estructura arquitectónica de influencia griega. Así, se ve cómo la influencia del drama griego se manifiesta desde un principio y se propaga externa e internamente en la obra de Eugene O’Neill.

Además, es importante recordar que un rasgo del teatro griego de la antigüedad es la presencia del coro, el cual es utilizado en la tragedia clásica para contextualizar, aclarar, o introducir comentarios para la audiencia, y así facilitar la comprensión e incluso la reacción esperada de las personas lectoras o espectadoras de la obra. El coro es en Esquilo “un auténtico personaje dramático, en todas las tragedias e incluso en algunas de ellas es el protagonista” (Fuentes González, 2007, p. 35).

Curiosamente, en la obra de O’Neill el coro está presente y es representado por personajes secundarios, tales como el jardinero, el carpintero, su familia y amigos, y la gente del pueblo en 
general, todos ellos caracterizados por ser amantes de los “chismes”. El mismo texto señala esta similitud, pues al referirse al carpintero, a su esposa y prima, dice: "Estos últimos tres personajes son tipos de la gente del pueblo más que individuos, se trata entonces de un coro representando al pueblo que se acerca a ver, a escuchar y a espiar a los ricos y exclusivos Mannons” (O’Neill, 1959, p. 228). ${ }^{2}$ Por lo tanto, según lo expuesto anteriormente, la función de proveer conocimiento y claridad para la persona espectadora, función propia del coro griego, no se da en el coro del drama realista de O’Neill, en donde chismes y rumores desvirtúan la realidad y enturbian o distorsionan los hechos.

El uso de máscaras es otra similitud que se observa en el drama de O’Neill con relación a la tragedia griega clásica. Es propicio recordar que en el teatro griego la máscara se utilizaba para que un mismo actor pudiese interpretar varios personajes y para que los gestos característicos de determinados sentimientos, bien marcados y acentuados en el diseño de las máscaras, quedaran más explícitos al público. En la obra de O’Neill, la imagen de la máscara se logra en la misma descripción de los personajes. Por ejemplo, al describir a Christine Mannon, el texto indica: "Su rostro es inusual, atractivo más que hermoso. Uno se sorprende por la extraña impresión que el mismo da de reposo en lugar de un rostro de carne viviente, como si fuera una pálida y hermosa máscara” (O’Neill, 1959, p. 230). ${ }^{3}$

Sin embargo, la alusión a la máscara en la obra de O’Neill no es tan funcional como en el teatro griego, sino que más bien actúa como símbolo de lo que Christine y otros personajes esconden, es decir, sus sentimientos, deseos y temores. Es tiempo entonces de enfocarse, para efectos de esta comparación literaria, en las similitudes de los dos personajes femeninos señalados al inicio: Clitemnestra y Christine Mannon.

\section{Similitudes en los personajes femeninos}

$\mathrm{Al}$ analizar las similitudes existentes en Clitemnestra y Christine Mannon, se observan varios aspectos o características que se repiten en las dos heroínas, y que resultan, a la vez, bastante negativas. En realidad, al referirse a la oposición binaria patriarcal que dicta que lo femenino está asociado con la pasividad, la oscuridad y el dolor, Mary Eagleton afirma que “(...) cada oposición puede analizarse como una jerarquía en donde el lado femenino es siempre visto como negativo y sin

\footnotetext{
2 Traducción propia del original: "These last three are types of townsfolk rather than individuals, a chorus representing the town come to see and listen and spy on the rich and exclusive Mannons”(O’Neill, 1959, p. 228).

3 Traducción propia del original: "Her face is unusual, handsome rather than beautiful. One is struck at once by the strange impression it gives in repose of being not living flesh but a wonderfully life-like pale mask” (O’Neill, 1959, p. 230).
} 
poder alguno” (Eagleton, 1996, p. 147). ${ }^{4}$ Ciertamente, estos dos personajes muestran varias características negativas, pero aun así, las dos heroínas están provistas de poder. Al ser comparadas, se nota que ambas mujeres experimentan un periodo de ausencia conyugal durante el cual se hacen de un amante, es decir, ambas son infieles. Asimismo, las dos niegan esta relación extramarital y proclaman el supuesto amor que sienten por sus esposos, por lo tanto, ambas mienten. Por ejemplo, al expresarse sobre su papel como esposa, Clitemnestra afirma: “ (...) Que a su esposa / a su regreso, tan fiel, / hállela cual la dejara/ al partir, tal como un perro/ guardián de la morada, / tierna con él mas hostil / con los extraños (...)” (Esquilo, 2013, p. 264). Por su lado, Christine hipócritamente recibe a su esposo con ternura y muestra un falso interés en él al decirle: “Qué galante has vuelto, Ezra. Debes de estar muy cansado. ¿No te gustaría sentarte aquí en las gradas por un rato? La luz de luna está tan hermosa” (O’ Neill, 1959, p. 263). ${ }^{5}$ Y cuando Ezra Mannon, tomando en cuenta una información que le fue dada, le pregunta a su esposa sobre un posible interés de ella hacia Adam Brant, Christine lo niega todo, considerándolo un comentario ridículo y sin sentido. El coro lo corrobora con las palabras y acciones de Clitemnestra, en tanto que Lavinia, hija de Christine, cataloga de mentirosa a su propia madre.

Además, las dos mujeres son descritas como manipuladoras: Clitemnestra convence a Agamenón para que pise el tapiz o alfombra de recibimiento, culto que debe ser conferido solo a los dioses, pues realizarlo por simples mortales puede traer consecuencias nefastas. Agamenón lo indica al decir: "Es a los dioses/ a quien hay que rendir este homenaje. / Un hombre soy: me causa escalofríos / caminar sobre estos ricos bordados” (Esquilo, 2013, p. 279). Sin embargo, el rey Agamenón accede a lo dispuesto por Clitemnestra cuando esta le dice: “Aunque eres vencedor, cede a mis ruegos” (p. 280).

Por su lado, Christine Mannon convence a su amante, Adam Brant, de que matar a Ezra Mannon, su esposo, es la única forma de poder estar juntos, para que así Adam le ayude en su plan de asesinato. Brant tiene dudas sobre el crimen y, entonces, Christine lo tacha de cobarde y le dice: “Si me amas tanto como dices, pensaría que puedes quitarte cualquier escrúpulo” (O’Neill, 1959, p. 258). ${ }^{6}$ Entonces, para probar su amor, Brant le contesta: “Haré cualquier cosa que quieras” (ibidem). ${ }^{7}$ Y así Brant accede a lo que su amada le propone, ser cómplice de un asesinato.

\footnotetext{
4 Traducción propia del original: “(...) each opposition can be analysed as a hierarchy where the ‘feminine’ side is always seen as the negative, powerless instance” (Eagleton, 1996, p. 147).

${ }^{5}$ Traducción propia del original: “How gallant you’ve become, Ezra. You must be terribly tired. Wouldn’t you like to sit here on the steps for a while? The moonlight is so beautiful” (O’Neill, 1959, p. 263).

${ }^{6}$ Traducción propia del original: "If you love me as much as you claim, I should think that would rid you of any scruples!”(O’Neill, 1959, p. 258).

7 Traducción propia del original: “I will do anything you want” (ibidem).
} 
Partiendo de la clasificación de la mujer arquetípica, se observa cómo ambas heroínas muestran características de la Terrible Mother (Guerin, 2005, p. 187), conocida también como femme fatale, la mujer que utiliza su sensualidad para convencer a los hombres a su antojo y poder realizar fines macabros. Siguiendo con la comparación de características y acciones de estos personajes femeninos, es posible distinguir que ambas mujeres son asesinas, pues matan al esposo después de una ausencia prolongada tras regresar de una guerra: la guerra de Troya en el caso de Agamenón, y la guerra civil estadounidense en el caso de Ezra Mannon.

\section{Diferencias en los personajes femeninos}

No obstante, al explorar el accionar de estas dos mujeres, se perciben diferencias importantes entre la reina Clitemnestra y Christine Mannon. Clitemnestra, además de tener un amante, tiene una justificación para cometer el crimen contra su esposo, ya sea por odio o por rencor, pues Agamenón sacrificó a su propia hija, Ifigenia, para honrar a los dioses y así solicitarles ayuda para ganar la guerra de Troya. Entonces, la reina Clitemnestra proclama después de cometer el crimen: "Este es Agamenón, cadáver ya, mi esposo, /muerto a los golpes de mi mano, (...) [quien] osó sacrificar—el parto más querido de mi vientre—_a su hija, para hechizar los vientos / de Tracia” (Esquilo, 2013, pp. 304-305). En su caso, Christine no tiene otra razón aparente para cometer el crimen más que el desamor y aversión que siente hacia su esposo, sumado a su deseo de estar con su amante. De esta forma, le dice a Mannon cuando este le reprocha su actitud: “Me llenaste de asco” (O’Neill, 1959, p. 275). ${ }^{8}$

Clitemnestra afirma que ella misma "ha tiempo había preparado este proyecto [el asesinato de Agamenón]” (Equilo, 2013, p. 303), y por esto, además de ser considerada insensata y maldita según el coro, será despreciada por todo el pueblo al llamarla "mujer sin patria, odio implacable de tu propia tierra” (p. 305). No obstante, el Corifeo considera a Egisto, amante de Clitemnestra, como el verdadero autor intelectual del crimen, y el mismo Egisto lo confirma al decir: “(...) poner la trampa, era la esposa quien lo debía hacer” (p. 315), pues Egisto era considerado como un "enemigo sospechoso” del rey. Es decir, según la visión patriarcal, el ámbito de lo intelectual, del pensamiento o razón, debe ser regido por el hombre, y la mujer debe ser relegada a un rol secundario, en este caso, al de cómplice.

Lo contrario se visualiza en Christine, quien no es solamente la ejecutora del asesinato, al envenenar a su esposo, sino también la autora intelectual de dicho crimen. Christine planea y

${ }^{8}$ Traducción propia del original: “You filled me with disgust” (O’Neill, 1959, p. 275). 
convence a Adam, quien no está dispuesto en un principio a participar en el homicidio, de ser su cómplice. Para lograr su objetivo, ella primero tacha a Adam de cobarde, le recuerda el deseo de venganza que él siente por la muerte de su madre y, además, le presenta su complicidad en el asesinato como una forma de mostrarle su gran amor. Finalmente, Christine piensa en los aspectos e instrumentos que utilizará para llevar a cabo el crimen, como la afección cardiaca de Mannon, el uso de medicamentos y la compra de un veneno.

La maternidad es otra diferencia en estas dos mujeres. Clitemnestra, por su ira y su dolor de madre, asesina a su esposo para vengar la muerte de su hija Ifigenia. La ve parte de sí misma, sacrificada injustamente por el deseo de poder de los hombres. Así, la reina exclama: "Por total justicia de mi hija, / (...) en cuyo honor he cometido el crimen” (Esquilo, 2013, p. 306). Reflexionando sobre la maternidad, Julia Kristeva habla sobre la división del ser en la mujer al ser madre, cuyo estado, según esta autora, conduce a la madre a vivir una experiencia compleja, en la que requiere sentir el amor por otro y no por sí mismo (citado en Gilbert y Gubar, 2007, p. 469). Este amor es evidente en Clitemnestra.

En cambio Christine, aunque se preocupa por su hijo Orin, quien está en la guerra, engaña, atormenta y rivaliza con su hija Lavinia, quien, siguiendo la trilogía griega de Esquilo, asumiría el papel de Electra. Se observa entonces que Christine no puede desarrollar el amor materno definido por Kristeva, al menos no con su hija Lavinia. Christine privilegia sobre su condición de madrela pasión que siente por su amante, e incluso utiliza a su propia hija para cubrir su adulterio. En todo caso, no se le puede criticar mucho, pues "si el castigo de Eva es (...) su condenación al dolor de la maternidad” (Gilbert y Gubar, 2000, p. 198), ${ }^{9}$ Christine, como mujer y descendiente de Eva, prefiere ignorar dicho legado y buscar su propio placer.

\section{Temas recurrentes en las figuras femeninas: poder, justicia, venganza}

La comparación de personajes literarios que se presenta en este artículo se ubica sin duda en el campo de la literatura comparada. Dicho campo es considerado “(...) un campo de campos que llevan a fronteras vistas como oportunidades para ser cruzadas” (Saussy, 2006, p. 18), ${ }^{10}$ y en esta comparación de los personajes femeninos de Esquilo y de O’Neill, hemos cruzado fronteras en el tiempo y en el espacio. Además de esta expansión y flexibilidad académica, el campo de la literatura

\footnotetext{
${ }^{9}$ Traducción propia del original: "If Eve’s punishment (...) is her condemnation to the anguish of maternity" (Gilbert y Gubar, 2000, p. 198).

${ }^{10}$ Traducción propia del original: “(...) a field of fields drawn to boundaries as opportunities for boundary crossing” (Saussy, 2006, p. 18).
} 
comparada ofrece diversas formas de comparación, es decir, ya sea a nivel genérico, estructural, mítico o temático, entre muchas otras. Las obras que analizadas tienen potencial para seguir cualquiera de estos enfoques, pero debido a la recurrencia en ambasde los conceptos de poder, justicia y venganza, es pertinente realizar una comparación a nivel temático de estos mismos apartados, la cual servirá para explorar un poco más el accionar de estas dos mujeres de construcción literaria.

Michel Foucault señala que "el poder es simultáneamente parte de la realidad material y social” (citado en Wolfreys, 2004, p. 197). El poder es algo que debe rescatarse en este estudio, pues los dos personajes femeninos son mujeres fuertes y poderosas, lo cual no es tan común en el discurso patriarcal y en los contextos sociales en donde vivieron, ya que ambas estuvieron casadas con hombres de gran poder dentro de sus respectivas sociedades. Además, se debe recordar que "en la sociedades patriarcales en las que los hombres se perciben como seres superiores es ‘apropiado’ y ‘correcto’ para ellos tener poder en la esfera pública y privada” (Meyers y Pacheco, 2011, p. 6). No obstante, tanto Clitemnestra como Christine gozan de poder.

Clitemnestra tiene poder de autoridad, pues es la reina y el rey está ausente. De ahí que el Corifeo le diga: "He venido a rendir mi pleitesía, a tu augusto poder, oh Clitemnestra/ Que es justo honrar del príncipe a la esposa/ si está vacío el trono del marido” (Esquilo, 2013, p. 246). Por lo tanto, no es de extrañar que el vigía, acatando las órdenes de la reina, dice haber estado en la azotea del palacio de los Atridas durante todo un año, esperando ver la antorcha que comunicara la conquista de Troya, “pues así lo ha mandado de una esposa/ el varonil e impaciente pecho” (Esquilo, 2013, p. 235). Es interesante notar el uso del adjetivo "varonil”, referente de lo masculino, para describir el pecho de Clitemnestra. Pareciera entonces que solo lo referente a lo masculino es digno de poder y obediencia. Además, contradiciendo la imagen de dulzura y pasividad de lo femenino, según la perspectiva patriarcal, Clitemnestra habla con voz autoritaria y enérgica. Por ejemplo, cuando el Corifeo duda del triunfo de los griegos, la reina le contesta enfáticamente: “Que Troya es de los griegos. ¿No hablo claro?” (Esquilo, 2013, p. 247).

Christine no goza de poder de autoridad real, pero sí de poder socio-económico debido a su posición privilegiada, ya que al estar ausente su esposo, ella es la voz autoritaria de la casa. Por lo tanto, al descubrir que su hija Lavinia le dio permiso al jardinero para que trajera a sus amigos para contemplar la mansión de los Mannon, Christine le dice enérgicamente a su hija: "Y desde cuando tienes el derecho de hacerlo sin consultarme” (O’Neill, 1959, p. 237). ${ }^{11}$ Sin embargo, el mayor poder de Christine es el de manipulación y el de convencimiento. Este se observa en la forma en que recibe

\footnotetext{
${ }^{11}$ Traducción propia del original: “And since when have you the right without consulting me” (O’Neill, 1959, p. 237).
} 
a su esposo y en cómo logra de él lo que ella quiere, o en la forma de convencer a su amante para que sea su cómplice en el asesinato de Ezra Mannon.

El segundo tema que caracteriza al proceder de estas dos damas es el de la justicia. Vista como sentimiento de equidad y como el respeto a los derechos de los individuos y de las organizaciones (Florían, 2002, p. 151), la justicia es tema recurrente en la obra de Esquilo, en donde se repite una y otra vez, por ejemplo, en los siguientes versos: “¡entona el canto lúgubre, sí, lúgubre,/ pero que al final, se imponga la Justicia” (Esquilo, 2013, p. 242). Llama la atención el uso de la mayúscula en la palabra 'justicia' del verso anterior. Clitemnestra incluso personifica este concepto al exclamar, cuando llega su marido: “(...) Salga un sendero / de púrpura a su paso, y que Justicia / lo conduzca a un lugar que no esperaba” (Esquilo, 2013, p. 278), es decir, el lugar donde se ejecutará un crimen, al encuentro con su propia muerte. Y, finalmente, cuando Egisto, amante de Clitemnestra, se entera de la realización del asesinato de Agamenón, exclama: “¡Oh dulce luz de un día justiciero!” (p. 312). Nuevamente, el concepto de justicia se asocia con los temas de venganza y muerte.

Por su lado, Christine utiliza el concepto de justicia para sus propios fines. Es importante recordar que Ezra Mannon era un juez. En el retrato que se encuentra en su estudio, Mannon aparece con una túnica negra, típica vestimenta de los jueces de la época. En esa foto su rostro también tiene la semblanza de una máscara. Cabe destacar que Christine nunca olvida que su esposo fue juez antes de ser general de guerra, y así se lo dice a su amante: “No te olvides que él era un juez. Él no lo olvidará” (O’Neill, 1959, p. 254), ${ }^{12}$ aludiendo posiblemente al hecho de que ellos serán juzgados por sus actos. Pero, además, Christine utiliza la justicia para lograr llevar a cabo sus objetivos. Ella le dice a su amante: "Si él [Mannon] fuera asesinado, nosotros podríamos casarnos y yo te daría lo que me toca de la fortuna de los Mannon. Eso sería justicia” (p. 256). ${ }^{13}$ Se corrobora cómo la distorsión del concepto de justicia es grande, pues para la heroína de O’Neill la justicia pareciera ser sinónimo de conveniencia, interés o venganza.

Por consiguiente, no es de extrañar que el tercer tema, precisamente la venganza, se use con frecuencia en las palabras y procederes de estas dos mujeres, y que también esté ligado al tema de justicia, pues para ellas la venganza es considerada un medio de hacer justicia y para lograrla necesitan tener poder. Siguiendo esta línea de pensamiento, lo justo es que Agamenón sea asesinado por haber sacrificado a Ifigenia, y que ella muera para pagar por el crimen de su padre al asesinar a

\footnotetext{
12 Traducción propia del original: “Don’t forget he used to be a judge. He won’t forget it” (O’Neill, 1959, p. 254).

13 Traducción propia del original: "If he [Mannon] had only been killed, we could be married now and I would bring you my share of the Mannon estate. That would only be justice” (O’Neill, 1959, p. 256).
} 
sus propios sobrinos, los hijos de Tieste. Igualmente, Agamenón debe morir, pues es "el destructor de ciudades” y ha destruido en ellas los altares de sus dioses. Incluso Casandra, la hija clarividente de Príamo, cuando se dirige a su eminente muerte en manos de Clitemnestra, exclama: “(...) al Sol suplico, en esta luz postrera, / que el Vengador, al tiempo, también vengue / mi muerte (...)” (Esquilo, 2013, p. 300). Se observa entonces cómo la venganza se clama o ejecuta en la obra de Esquilo.

El tema de venganza está también presente en la obra de O’Neill. No queda claro el porqué Christine dejó de amar a Ezra Mannon después de casarse con él, ella solo dice: "Pero el matrimonio pronto transformó su romance en aversión” (O’Neill, 1959, p. 249). ${ }^{14}$ Por consiguiente, Christine no soporta que su esposo la toque siquiera, y cuando este le pregunta por qué no lo ama, ella le dice que aunque ha engendrado hijos de él “(...) Nunca he sido tuya” (p. 275). ${ }^{15}$ Así, Christine se venga diciéndole esta verdad a Ezra, sabiendo que él la ama, que está mal del corazón y que dichas palabras perjudicarán su salud. Siguiendo con la temática de venganza, Ezra Mannon también debe ser asesinado para que Adam Brant pueda vengar la muerte de su madre, como también puede vengar su imposibilidad de reclamar algún derecho del patrimonio de los Mannon que, por consanguineidad, le corresponde. Además, según Lavinia, Adam Brant no está verdaderamente enamorado de su madre, y así le dice a Adam: "Ella es solo la forma de vengarte de mi padre” (p. 245). ${ }^{16}$ Un medio, un fin, el motivo para cometer un crimen, la venganza está por doquier en la obra de Eugene O’Neill.

Por ende, al repensar los temas de poder, justicia y venganza, se observa que en las dos heroínas están presentes estos tópicos, los cuales forman un triángulo de articulación en el cual las relaciones entre los tres son innegables y necesarias para el accionar de los personajes. El poder es necesario para hacer justicia y la mayor parte del tiempo la justicia es visualizada como sinónimo de venganza, tanto en el “Agamenón” de Esquilo como en el “Homecoming” de O’Neill.

\section{Conclusiones}

Después de la comparación realizada de estas obras literarias, se observa cómo los elementos del drama griego que adopta O’Neill tienen una función opuesta a la que se les daba en el drama clásico. El coro, transformado en un grupo de personajes chismosos, en lugar de esclarecer los hechos al lector, los distorsiona. La máscara, representada en la descripción de la fisonomía de los personajes,

\footnotetext{
14 Traducción propia del original: “But marriage soon turned his romance into—disgust!” (O’Neill, 1959, p. 249).

${ }^{15}$ Traducción propia del original: “(...) I’ve never been yours! (O’Neill, 1959, p. 275).

${ }^{16}$ Traducción propia del original: “She is only your means of reveange on Father” (O’Neill, 1959, p. 245).
} 
en vez de revelar los sentimientos de estos al espectador, los oculta. La complejidad de entendimiento es característica recurrente en la obra de O’Neill, no solo en los elementos utilizados sino en los mismos personajes. El crimen de Clitemnestra es justificable al considerar el sacrificio de su hija Ifigenia, pero el crimen de Christine no es tan comprensible, y hasta resulta cruel, calculador y despiadado. Pareciera que al pasar los siglos la confusión o complejidad de entendimiento o de comprensión humana aumenta, mientras que la violencia se perfecciona volviéndose menos justificable.

El drama realista de O’Neill titulado Mourning Becomes Electra presenta la versión de una Clitemnestra del siglo XX. La esposa que atrapa a su marido tendiendo una red sobre él para luego asesinarlo, como describió Esquilo a Clitemnestra en el “Agamenón” de La Orestía, se transforma en la Christine Mannon de “Homecoming” en Mourning Becomes Electra. Es decir, se trata de una mujer que planea meticulosamente el crimen de su esposo: sabiéndole enfermo, le debilita el corazón, confesándole que no lo ama, negándole la medicina que podría salvarlo y, finalmente, suministrándole veneno. O’Neill presenta más diálogo entre los esposos, a diferencia de Esquilo, y por eso los lectores visualizan mejor la tormentosa relación de los Mannon. Además, la persona lectora es testigo del asesinato de Ezra Mannon, mientras que en la obra de Esquilo es Clitemnestra quien relata con orgullo cómo se llevó a cabo el homicidio de Agamenón. ¿Qué es peor: ser testigos de un crimen o imaginarlo?

Sin embargo, no debe olvidarse que Clitemnestra y Christine Mannon son construcciones literarias creadas por dramaturgos que siguen la mentalidad patriarcal de sus respectivos tiempos y sociedades, pues como bien lo indica Adrienne Rich: “Tanto la victimización como la ira experimentada por mujeres (...) tienen fuentes reales (...) construidas en la sociedad, en el lenguaje, [y en] estructuras de pensamiento” (citada en Gilbert y Gubar, 2007, p. 199), ${ }^{17}$ y estas dos heroínas lo han demostrado en sus acciones y palabras.

Por consiguiente, Clitemnestra debe aparecer “demente” ante el pueblo para justificar su crimen, ya que, como lo dice el mismo Agamenón, “no es propio de mujer buscar la lucha” (Esquilo, 2013, p. 280) y menos la venganza. Además, en la obra de Esquilo los dioses son quienes definen el destino de los hombres y mujeres, y las acciones de estas son casi siempre condenadas. Por lo tanto, en la obra de Esquilo se destaca que es por una mujer que se ocasiona la guerra de Troya y es otra mujer la que asesina al gran rey de Argos. En otras palabras, el legado de Eva sigue su curso, pues el pecado, la traición y lo negativo se asocia con lo femenino. Como lo indican Gilbert y Gubar en el

\footnotetext{
${ }^{17}$ Traducción propia del original: "Both the victimization and the anger experienced by women (...) have real sources (...) built into society, language, [and] structures of thought” (citada en Gilbert y Gubar, 2007, p. 199).
} 
clásico The Madwoman in the Attic, la vulnerabilidad de Eva a las artimañas seductivas de Satanás la hace a la vez satánica (2000, p. 198). Y es que en las dos obras analizadas, a las heroínas se les considera locas o satánicas. Christine, por ejemplo, es ambiciosa, mentirosa e infiel, además de ser asesina. De este modo, ella debe aparecer ante el lector para así fortalecer la estructura de la obra dramática de O’Neill, en donde la tragedia no es provocada por el capricho de los dioses sino por los deseos y acciones de los mortales. No hay nada positivo en Christine Mannon, ella es la clásica femme fatale en un mundo convulso y confuso. Entonces, hay que preguntarse: ¿qué tan realista es este personaje, siendo el drama de O’Neill catalogado como realista?, ¿qué tan distorsionada está la imagen de la mujer para poder fortalecer el desenlace y la temática del drama?

Irónicamente, Agamenón y Ezra Mannon sobreviven la guerra, con todo el peligro y destrucción que esta implica y demanda, pero no visualizan ni sobreviven el accionar de sus propias esposas al regresar a casa. El coro griego dice: “El culpable a pagar/ Tal es la ley sagrada” (Esquilo, 2013, p. 311), pero entonces en estas obras, ¿quiénes son los culpables si son los esposos los que resultan asesinados? Al menos las respectivas esposas utilizan toda su fuerza, sin ningún remordimiento, para hacerlos sufrir. Después del homicidio ejecutado, Clitemnestra expresa: “¿No fue él, acaso, quien trajo la desgracia a mi familia?/ Por el dolor que causó injustamente/ al ser que de él brotara,/ la llorada mil veces Ifigenia,/ ique sufra justamente!” (Esquilo, 2013, p. 310). Y Christine, sabiendo que va a herirlo, le dice cara a cara a su esposo: "Sí, me atrevo (...) Él [Adam, su amante] es gentil y tierno, él es todo lo que tú nunca has sido. Él es lo que yo he esperado todos estos años contigo——un amante! ¡Lo amo!” (O’Neill, 1959, p. 276). ${ }^{18}$

En suma, el “Homecoming” 19 de “Agamenón”, al igual que el retorno de Ezra Mannon, resulta mortal. El luto [no solo] le sienta bien a Electra, sino que también les sienta bien a Christine Mannon y a Clitemnestra, quienes logran con éxito llevar a cabo sus planes. ¿Son mujeres villanas o vengadoras o acaso víctimas? Los lectores serán quienes lo decidan, pero sí sabemos que ellas son imágenes literarias femeninas, creaciones de escritores masculinos y representaciones de construcciones sociales. Por ende, son mujeres textuales, cuyos actos pueden ser comprendidos o condenados.

\footnotetext{
18 Traducción propia del original: “Yes, I dared! (...) He [Adam, her lover] is gentle and tender, he’s everything you've never been. He’s what I've longed for all these years with you—a lover! I love him!” (O’Neill, 1959, p. 276).

${ }^{19}$ Este término se interpreta como “Regreso”, según traducción propia.
} 


\section{Referencias bibliográficas}

Bloom, H. (1997). The Anxiety of Influence: A Theory of Poetry. New York: Oxford University Press. Eagleton, M. (1996).Working with Feminist Criticism. Massachusetts: Blackwell Publishers.

Esquilo. (2013). Tragedias completas. Madrid: Cátedra Letras Universales.

Florían, V. (2002). Diccionario de Filosofía. Bogotá: Panamericana Editorial.

Fuentes González, P. (2007). Los elementos estructurales del drama griego antiguo: forma y función. Florentina Iliberritana: Revista de Estudios de Antigüedad Clásica, (18), 27-67.

Gilbert, S. y Gubar, S. (2000). The Madwoman in the Attic: The Woman Writer and the NineteenthCentury Literary Imagination. New Haven: Yale University Press.

Gilbert, S. y Gubar, S. (2007). Feminist Literary Theory and Criticism. New York: W.W.Norton \& Company.

Guerin, W. (Ed.). (2005).A Handbook of Critical Approaches to Literature. New York: Oxford University Press.

Koelb, C. y Noakes, S. (1988). The Comparative Perspective on Literature: Approaches to Theory and Practice. Ithaca: Cornell University Press.

Meyers, K. y Pacheco, G. (2011). Women and/in Literature: Unique Voices, Shared Visions. San José, Costa Rica: Editorial UCR.

Moi, T. (2005). Sex, Gender, and the Body. New York: Oxford University Press.

O’Neill, E. (1959). Three Plays of Eugene O’Neil. New York: Vintage Books.

Saussy, H. (2006). Comparative Literature in an Age of Globalization. Baltimore: The Johns Hopkins University Press.

Wolfreys, J. (2004). Critical Keywords in Literary and Cultural Theory. New York: Palgrave Macmillam.

\section{(c) (1) $\Theta \Theta$}

Esta obra está bajo una licencia de Creative Commons Reconocimiento-NoComercial-

\section{SinObraDerivada 4.0 Internacional}

